\title{
High-Speed Sharpening and Thermo-activated Refinement of Blade Tools from Synthetic Diamonds
}

\author{
János Kundrák ${ }^{1}$, Vladimir Fedorovich ${ }^{2}$, Angelos P. Markopoulos ${ }^{3}$, Dmitry Romashov², Ivan Pyzhov ${ }^{2}$ \\ ${ }^{1}$ Institute of Manufacturing Science, University of Miskolc, Egyetemváros H-3515 Miskolc, Hungary. E-mail: \\ kundrak@uni-miskolc.hu \\ ${ }^{2}$ National Technical University "Kharkov Polytechnic Institute", 2 Kirpichova street, Kharkov, 61002, Ukraine. E- \\ mail: fedorovich@kpi.kharkov.ua \\ ${ }^{3}$ Laboratory of Manufacturing Technology, School of Mechanical Engineering, National Technical University of \\ Athens, Heroon Polytechniou 9,15780 Athens, Greece. E-mail: amark@mail.ntua.gr
}

Processing of synthetic diamonds is accompanied by low productivity and high values of relative consumption of diamond wheels. The coefficient of use of diamond grains in these processes does not exceed $5-10 \%$. Using synthetic diamonds as a blade tool, requires sharpening and refinement. This study proposes to use ultra-high-speed machining modes and the same diamond grinding wheel at all stages of tool shaping. At the first stage, i.e. at high speeds, a rough productive sharpening of diamond blade tool is made with a wheel on an iron-based binder. At the second stage processing speed is reduced, as a result grains cease to self-sharpen and to wear out. When the iron binder comes into contact with the sharpened diamond, the speed must be increased, so that the temperature in the contact zone of the binder with the rough surface of the cutter, increases. Due to diffusion wear, from the surface of the diamond, the height of the roughness micro-hills decreases. In other words, the process of high-quality thermally activated refinement of the working surface of the diamond cutter starts to be implemented.

Keywords: High-speed Diamond Grinding, Diffusion Wear, Finite Element Method, Tool Sharpening, Surface Roughness, Refinement

\section{Introduction}

Synthetic diamond (SD) is a unique material in its physical-mechanical properties, which is widely used in creating blade tools for various industries. Nevertheless, the inherent advantage of being one of the hardest known materials, becomes a drawback in refinement and sharpening of such tools. The role of the sharpening tool is essential, since, from its quality, depends the performance and efficiency of the blade. In fact, SD tools with appropriate quality of sharpening and finishing can replace natural diamonds $[1,2]$.

For the various industrial sectors, the cost effective and efficient production of diamond cutting tools with highly integrated edge quality is of extreme interest. Non-conventional processes like ion beam polishing, laser beam machining, electro-discharge machining, plasma etching, and chemical and thermo-chemical polishing have been suggested [3, 4]. Nevertheless, these methods have prohibitively low removal rate, which is an insurmountable limitation for efficient tool making [5], while the existence of a heat affected zone (HAZ) on the transverse face requires further processing, resulting in extra cost and time [6]. Commonly, the sharpening of a SD-made blade tool is done mechanically by polishing, using fine grain powder and lap plates of soft materials. That method is based on two main sub-processes, a preliminary grinding with a metal bonded wheel, and the subsequent refinement employing fine grained wheels with organic binders $[1,6,7]$. Similarly with the aforementioned non-conventional machining processes, the main disadvantage is the low productivity rate, especially at the final stage, due to the material's mechanical properties. More specifically, the machining tool and the workpiece have practically the same micro-hardness, thus it is crucial to provide the prerequisites for activating the process of removing stock at all stages of machining.

Abrasive processes have been studied experimentally and theoretically as well, including research regarding the mechanisms of grain wear during the wheel grinding process [8-10], and the optimum machining parameters for efficient grinding [11-13]. Additionally, advanced methods like ultrasonic vibration assisted grinding [14], or hybrid methods for sharpening tools by using nanosecond laser [15], have been presented and proposed by researchers. Theories, like the brittleductile transition, have been adopted to study the undergoing removal mechanism in lapping [16], while modeling and simulation have been employed, aiming to a better comprehension of the processes $[17,18]$. 
Researchers have concluded that cutting speed is an essential parameter for efficient and sustainable grinding [19-22]. As the cutting speed increases, each abrasive grain removes thinner material layer, resulting in changes in the chip formation mechanism, as well in the whole process [23-25]. For processing hard/superhard alloys and polycrystalline materials with SD wheels, higher peripheral speed is usually employed, since a preferable wear mechanism is obtained, see Fig. 1. The latter results in an increased cutting ability and material removal rate. Furthermore, in ultrahigh speeds, i.e. above $180 \mathrm{~m} / \mathrm{s}$, diamond grains are not abraded, but instead, micro-cracks are occurring, forming sharp micro and submicron cutting edges, leading that way in reduced cutting forces [21, 23]. Moreover, increased peripheral grinding speed results to lower wear rate of the abrasive working surface of the wheel (WSW), while improved machined surface quality can be achieved, as lower cutting forces are developed [26].

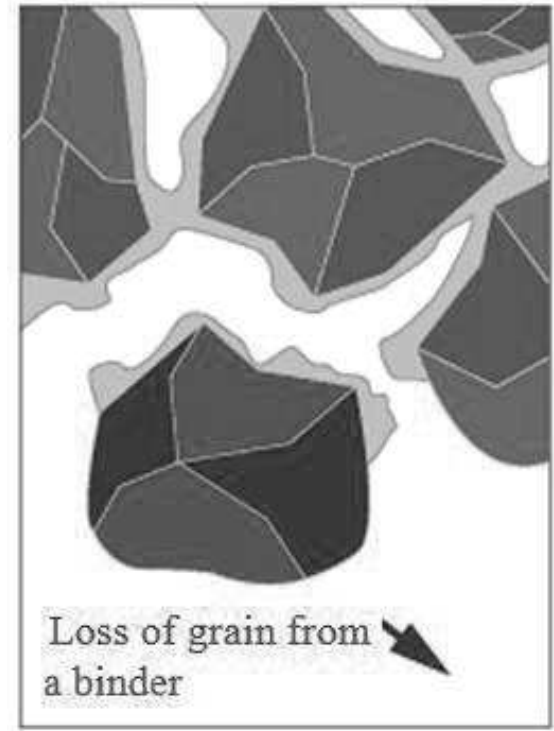

(a)

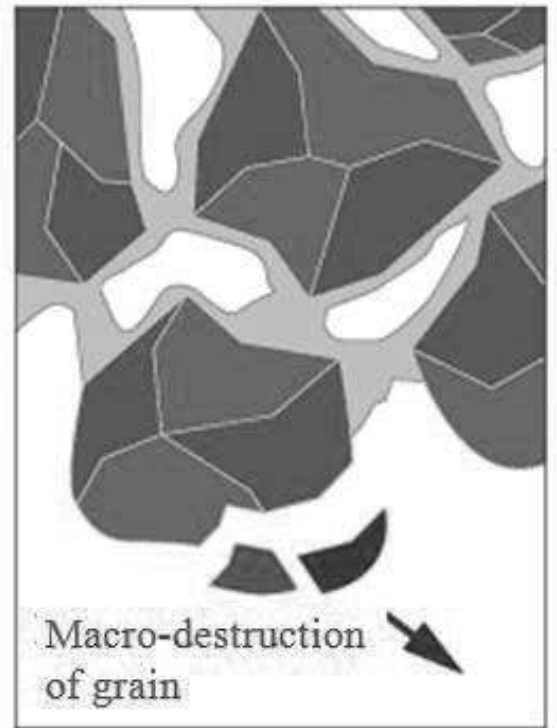

(b)

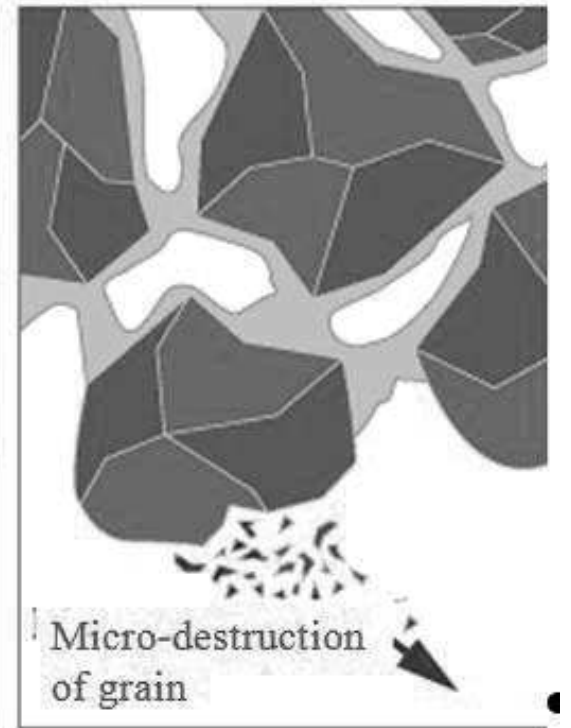

(c)

Fig. 1 Change in the mechanism of destruction of diamond grains with increasing processing speed $V$ at (a) $V=30 \mathrm{~m} / \mathrm{s}$, (b) $V=100 \mathrm{~m} / \mathrm{s}$ and $(\mathrm{c}) V=180 \mathrm{~m} / \mathrm{s}$.

The current paper presents a study regarding the sharpening and thermo-activated refinement of blade tools, aiming in increased productivity, and higher machined surface quality. Diamond wheels with iron based binders were used, while the rotation speed is the primary controlling parameter. As a novelty, this study proposes the use of the same diamond grinding wheel at all stages of tool shaping, at ultra-high-speeds.

\section{Research Methodology}

Based on the features of SD as an instrumental material, as well as the processes of shaping tools based on SD, a methodological approach to research was determined. Since a quantitative analysis of the highspeed sharpening process and thermally activated refinement of a blade tool made of SD requires an assessment of the wear rate of diamond grains and the volume of removed material from the machined surface of SD, a modern laser scanning method was used to determine the 3D topography of the WSW and the machined surface of SD.

The 3D topography of the WSW and the surface of the SD were studied on a Perthometer S8P laser scanning device with a FOCODYN laser sensor, the vertical resolution range of which was $\pm 250 \mu \mathrm{m}$, which is quite sufficient to measure the height parameters of the WSW of wheels with grain size up to $630 / 500$. The device allows to simultaneously record 9 selected from 86 possible parameters of the WSW topography. Its significant advantage is the synchronous computer processing of measurement results. This technique dramatically expands the scope of research, reduces labor costs and increases accuracy. Laser measuring center allows to obtain a visual image of 3D topography of WSW either directly (positive) or its imprint (negative), indicated in Fig. 2 by NEG symbol. The topography of the WSW can be obtained both by taking into account the undulation of the surface or without it, i.e. in filtered form.

Analysis of the surface of the replica (NEG) WSW shows that the bulk of the grains fall out of the binder only in the first seconds of grinding, i.e. the parameters of the WSW negative in the protruding part are almost the same for three seconds and two minutes of grinding, by comparing Fig. $2 \mathrm{a}$ and Fig. 2b. It can be argued that after three seconds of grinding, the main wear of the grains occurs due to their brittle microdestruction rather than loss from the binder. 


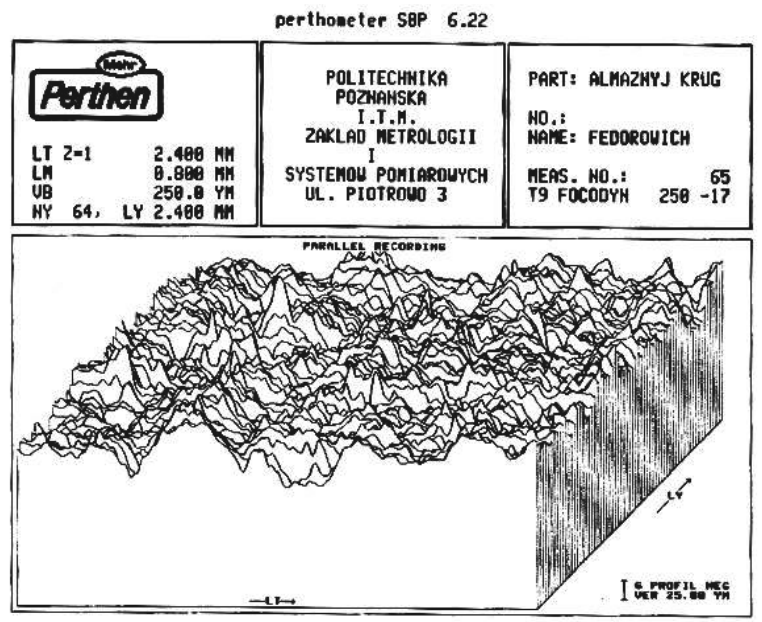

a)

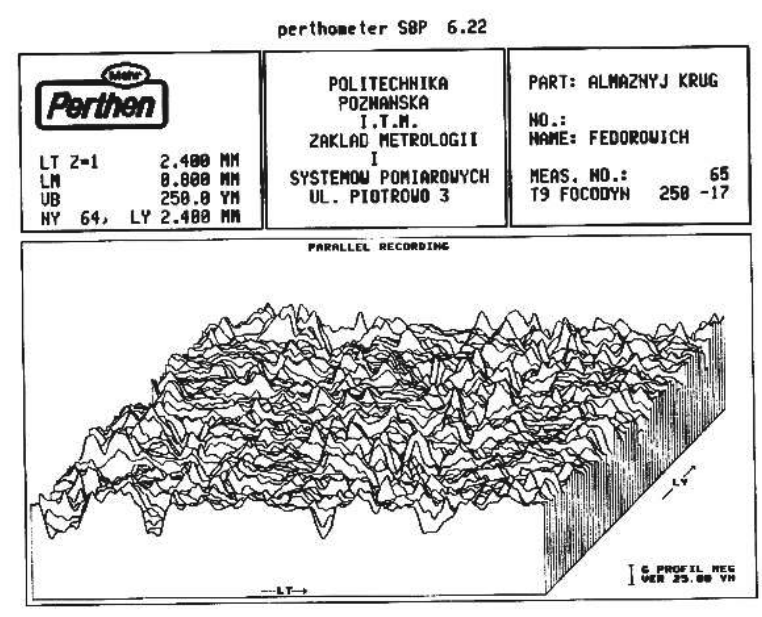

b)

Fig. 2 Negative 3D topography of the WSW (a) after 10 s and (b) after 2 min of grinding.

The main problem of processing SD is that abrasive materials, the hardness of which would exceed the hardness of diamond are not yet available and by the amount necessary from the point of view of the efficiency of the cutting process. That is, in the case of using diamond wheels for the treatment of $\mathrm{SD}$, it is possible to provide only an approximate equality of the microhardness of the processed and processing materials.

The removal of stock from SD in such conditions is carried out mainly due to the fragile micro-destruction of its surface layer. To implement this process, high pressures are required in the contact zone of diamond grains with SD. For the latter, there must be sharp micro and sub-micro-edges on the working surface of the grains of the wheel. In this regard, in relation to the process of diamond grinding of SDs, when the incorporation of diamond grains into the surface of the SDs is practically absent, the micro and submicro-edges of diamond grains work mainly. The mi- cro relief parameter of these edges is of particular interest. When studying the 3D topography of a WSW with a small scanning step, in our case equal to 2.38 $\mu \mathrm{m}$, a laser beam passed through each diamond grain $100 \mu \mathrm{m}$ in size more than 30 times. Using this technique allows the confirmation of the effectiveness of the use of ultrahigh grinding speeds for the forced formation of cutting micro - and sub-micro-relief on diamond grains. The study of such a parameter is of particular interest, as the relative reference surface area $\left(t_{\mathrm{ps}}\right)$, which largely determines the value of the actual contact area in the "WSW -SD" system. It allows to estimate the volumes of broken grains and removed allowance from the machined surface of the SD. Taking into account the fact that the value of elastic penetration of grain into SD does not exceed $0.5-1 \mu \mathrm{m}$, which was established during 3D modeling of the stress - strain state of the "SD - grain - binder" system [1], the value of $\mathrm{t}_{\mathrm{ps}}$ at the level of $1 \mu \mathrm{m}$ from protruding grain, i.e. at the level of $\mathrm{P}=5 \%$ at $\mathrm{h}_{\mathrm{P}}=20 \mu \mathrm{m}$, will be determined.

The laser scanning technique allows in 3D computer mode to determine the value of $t_{p s}$ both at the macro, i.e. the WSW, and at the micro level, i.e. submicro-relief of individual diamond grains and the processed surface of SD. The magnitude of the roughness of the working surface of individual diamond grains is an important parameter in determining the actual contact area in the SD-grain system, which is difficult to evaluate in other ways. The value of the relative reference area of the WSW profile (sub-micro-relief of grains) and the roughness of the treated SD surface at the level of $0-1 \mu \mathrm{m}$ will be used to determine the value of the actual contact area in the "WSW - SD" system.

The dynamics of the $t_{p s}$ parameter changes at the level of $\mathrm{P}=5 \%$, which is adequate to evaluate the actual contact area in the "SD-grain" system, indicates that for a newly opened by the electrochemical method diamond wheel with a metal binder (Fig. 3a) $t_{p s}$ grows slowly along the depth of the relief, which indicates a high sharpness of the grains, and $t_{\mathrm{ps}}$ in the worn wheel increases sharply due to mass formation of wear sites on grains (Fig. 3b). An analysis of the dynamics of changes in the $t_{\mathrm{ps}}$ parameter along the profile depth of the same wheel, but operating under different conditions, allows to estimate the change in the value of the actual contact area in the "WSW SD" system.

The considerable practical and methodological interest is the possibility of filtering parameters embedded in a laser scanning measuring center. It allows the separation of the waviness of the WSW macro profile from the relief of diamond grains above the binder level. This technique is especially important when analyzing the role of ultrahigh speeds in the formation of sub-micro-relief on diamond grains as a result of their self-sharpening. A significant advantage of this 
technique is the possibility of computer processing of the scan results and the construction of the laws of grain height distribution over the binder level, see Fig. 3(a) and Fig. 3(b), and their changes during grinding. Thus, the method of laser scanning of the WSW allows to reliably determine the laws of distribution of diamond grains above the level of the binder. Using the same methodology, the topography parameters of the machined SD surface, the faces and cutting edges of the cutters and their dependence on the processing conditions were also studied.

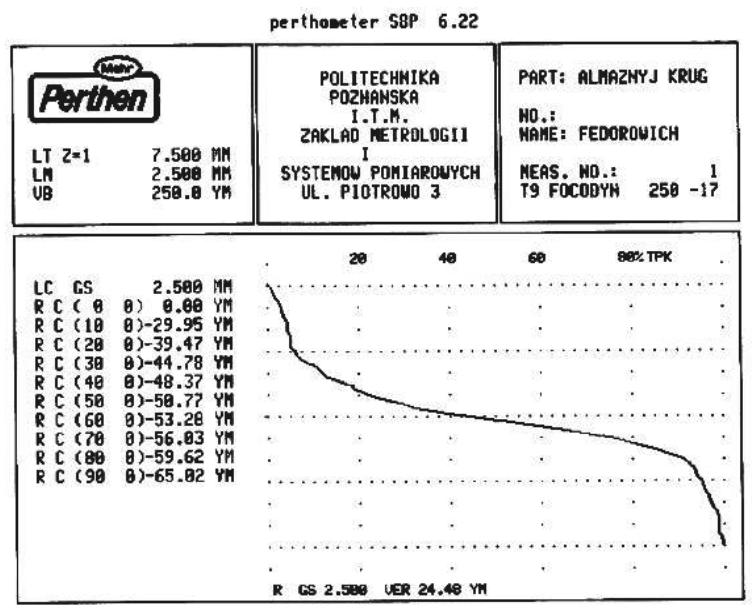

a)

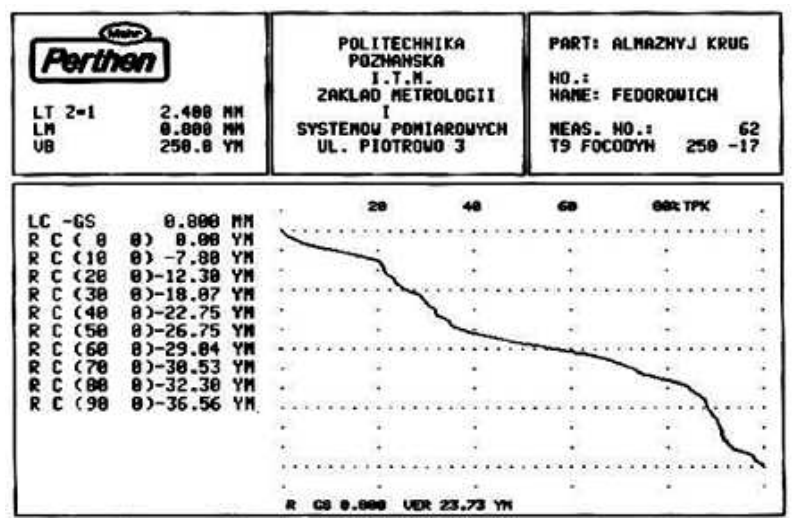

b)

Fig. 3 The relative reference area of the topography of the $W S W$ (a) after editing the wheel and (b) after 1 min of grinding.

\section{Results and Discussion}

It is known that SD blade tools are not recommended for the processing of ferrous metals due to the high degree of chemical affinity of interacting materials and, as a consequence, the high intensity of their wear. According to the data of [27, 28], the diffusion and oxidative types of wear are decisive in this case. In this regard, it can be assumed that after the diamond grains of the wheel are worn down to the level of an iron-based metal binder, the latter will contact the surface of the SD to be treated. As a result of this, diffusion and oxidative wear of micro-hills can take place, i.e. the process of thermally activated refinement of the diamond surface is carried out. A kind of replacement takes place: a diamond grinding wheel, i.e. its metal-containing binder becomes the processed material, and the surface of the $\mathrm{SD}$, its microroughness, acts as the smallest cutting tool - abrasive grain. In this case, an iron-based metal binder is used, which on the one hand provides strong retention of diamond grains, in the production process of ultra-high-speed processing, and on the other hand provides the maximum speed of diamond diffusion into the binder. The required high temperature for the diffusion process is ensured by friction of the binder with the treated SD. In fact, a process is being implemented that is similar to the process of finishing a diamond tool on a heated cast-iron disk [27].

Thus, the process of sharpening and refinement is carried out in three stages (transition): high-speed productive grinding, grinding at a traditional speed for 30$60 \mathrm{~s}$, at which the grains wear out to the level of the binder and binder comes into contact with the processed material [1] and grinding at increased speeds in order to effect diffusion wear (refinement) of the micro-hills of the treated SD due to high temperatures in the contact zone of the iron binder with diamond. Thus, it becomes possible to carry out preliminary and precision operations of machining a tool from SD with the same diamond wheel on a strong metal binder on an iron base.

An important element that determines the effectiveness of the process of thermally activated lapping is the temperature in the contact "WSW - SD". Based on the idealized scheme of the contact of the wheel with the processed polycrystalline diamond, see Fig. 4, under the condition that the grains wear to the complete contact of the binder with SD, the average temperature increase within a unit heated point at average sliding speeds can be obtained from the equation [29]:

Where:

$$
\theta=\frac{6.4 \mu N V}{b\left(\lambda_{1}+\lambda_{2}\right)}
$$

$\mu$ the coefficient of friction,

$\mathrm{N}$ the contact load $\left[\mathrm{N} / \mathrm{m}^{2}\right]$,

$\mathrm{V}$ the sliding speed $[\mathrm{m} / \mathrm{s}]$,

$\mathrm{b}$ the side of the contact square $[\mathrm{m}]$ and

$\lambda_{1}, \lambda_{2}$ the thermal conductivity of two sliding bodies $[\mathrm{Wt} /(\mathrm{mK})]$.

By taking $\mathrm{N}=2 \mathrm{MPa}, \mathrm{V}=30 \mathrm{~m} / \mathrm{s}, \mathrm{b}=60 \mu \mathrm{m}$, the temperature can be calculated for the case of contact of diamond with diamond, as well as diamond with $\mathrm{Fe}$, $\mathrm{Cu}, \mathrm{Ni}, \mathrm{Sn}$, the percentage of which, for example, in the M6-14 binder the greatest. The results of the calculations are presented in Table 1 , and they indicate the possibility of the appearance of sufficiently high temperatures, comparable with the temperatures of oxidation, diffusion, and even graphitization of SD. 


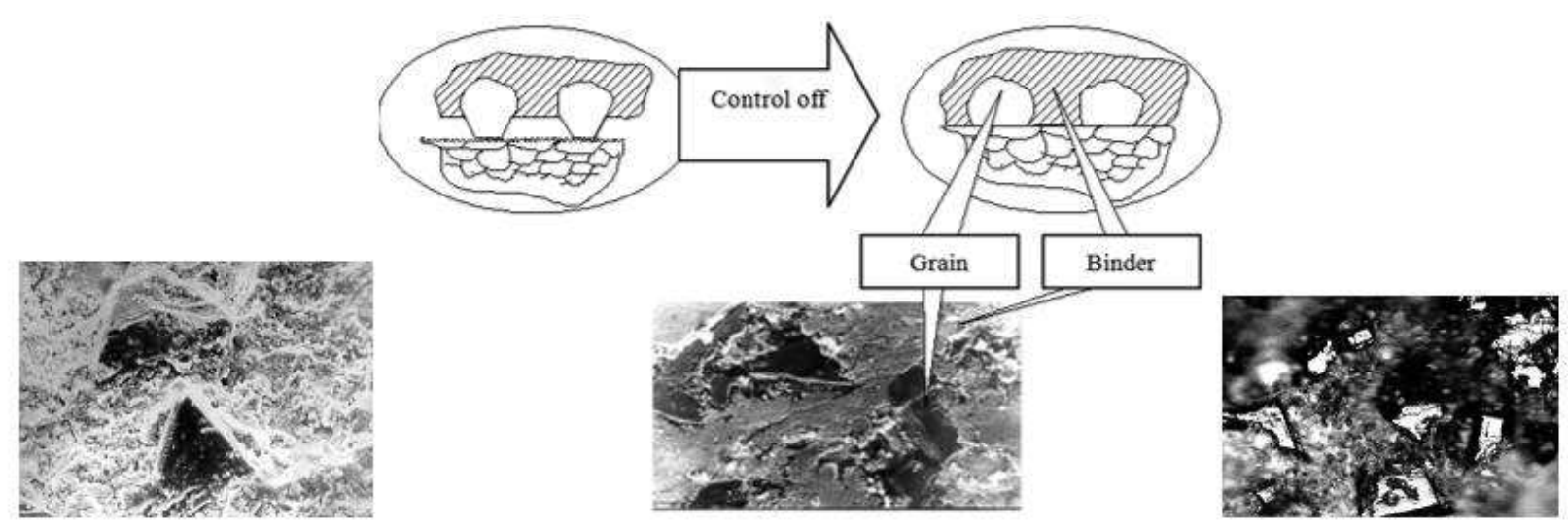

Fig. 4 Control the parameters of the WSW by changing the processing speed.

Tab. 1 Calculated Contact Temperatures of SD with V arious Diamond Wheel Components.

\begin{tabular}{|c|c|}
\hline Contact material & $\boldsymbol{\theta}\left[\mathbf{d e g} / \mathbf{m m}^{\mathbf{2}}\right]$ \\
\hline Diamond $(25 \%)$ & 1100 \\
\hline Iron $(51 \%)$ & 1100 \\
\hline Copper $(32 \%)$ & 1550 \\
\hline Nickel $(9 \%)$ & 1400 \\
\hline Tin $(8 \%)$ & 1000 \\
\hline
\end{tabular}

Roughly, the intensity of thermally activated lapping $\mathrm{Q}_{\mathrm{td}}$ can be defined as the sum of the intensities of the thermo-oxidative and diffusion processes:

$$
\mathrm{Q}_{\mathrm{td}}=\mathrm{Q}_{\text {diff }}+\mathrm{Q}_{\mathrm{ti}}
$$

Where:

$Q_{\text {diff }}$ the diffusion process intensity and $\mathrm{Q}_{\mathrm{ti}}$ the thermal oxidation process intensity.

In order to justify the possibility of thermally activated refinement, the results of studies on the wear of a diamond tool $[27,28]$ and the method of "fire drilling" for the wear of diamond ruling pencils [30] were used. The algorithm for quantifying the results of thermally activated refinement is as follows: determining the 3D topography parameters of the treated surface of the SD; determination of 3D topography parameters of the WSW; determination of the actual contact area in the "WSW -SD" system; Calculation of the intensity of the thermally activated lapping of the treated surface SD.

To determine the wear rate of a diamond polycrystalline caused by the destruction of the surface layer under the action of thermoelastic stresses, the "fire drilling" formula proposed in [30] was employed:

Where:

$$
Q_{O K}=\frac{A_{r} \lambda}{l \rho_{c}}\left[\frac{\alpha E T}{(1-\mu) \sigma_{s}}-1\right]
$$

$A_{r}$ the actual diamond contact area $[\mu \mathrm{m}]$, $\lambda$ the thermal conductivity of diamond [Wt/ $(\mathrm{m} \mathrm{K})]$, 1 the thickness of the heated surface crystal layer $[\mu \mathrm{m}]$, e the diamond density $\left[\mathrm{N} / \mathrm{m}^{3}\right]$, c the thermal conductivity $[\mathrm{J} /(\mathrm{kg} \mathrm{K})]$, $\alpha$ the coefficient of thermal expansion $\left[\mathrm{K}^{-1}\right]$, E Young's modulus of diamond $\left[\mathrm{N} / \mathrm{m}^{2}\right]$, $T$ the contact temperature $[\mathrm{K}]$,

$\mu$ Poisson's ratio and $\sigma_{\mathrm{s}}$ the compressive strength $\left[\mathrm{N} / \mathrm{m}^{2}\right]$.

The thickness of the heated near-surface layer of $\mathrm{SD}$ was taken as the average value of the height of microroughnesses on its contact surface formed during preliminary processing, i.e. grinding with control of the cutting relief of the wheel. The actual contact area of the SD with the grinding wheel was determined through the relative reference surface area obtained by computer processing the results of laser scanning of the corresponding surfaces [1] and the volume of material located in the rough layer with a depth corresponding to the maximum roughness level was determined. When choosing the values of thermal conductivity and heat capacity of diamond, the nature of their temperature dependence was taken into account and contact temperatures were taken based on data [1] The performance of thermally activated lapping, calculated by eq. (2), characterizes the rate of thermally activated destruction of the surface of SD at the stage of refinement and is $0.016-0.03 \mathrm{~mm}^{3} / \mathrm{min}$.

The results of laser scanning of the topography of the pre-machined surface of the SD, namely grinding with the control of the topography of the wheel, showed that the volume of material in a layer thick with a maximum surface roughness, which is parameter $\mathrm{Sv}$, on the front surface area of SD cutter is $4.8 \times 10^{-}$ $3 \mathrm{~mm}^{3}$. Thus, the theoretical volume of SD corresponding to the roughness of the pre-treated surface can be removed in $9.6 \mathrm{~s}$.

In addition to the thermo-oxidative process, at high temperatures in the contact of the binder based on iron with SD, diffusion removal of the SD material will also take place. Diffusion is considered to be a slow process, and its role is insignificant in the overall wear. However, studies conducted by the authors of 
$[27,28]$ showed that diffusion processes occurring upon contact of materials with chemical affinity dominate the overall wear. The same, authors note the following characteristic features of the occurrence of diffusion processes in the diamond - iron contact. According to [27], the resistance of a diamond cutter associated with diffusion wear depends significantly on temperature. Thus, for example, for a diamond tool when cutting ferrite, it can be determined by the formula [28]:

$$
\tau=\frac{0.627 l^{480^{o} / T^{o}}}{C_{0} V^{1 / 2}} c
$$

Where:

$C_{0}$ the interface solubility,

$V$ the cutting speed $[\mathrm{m} / \mathrm{s}]$,

1 the amount of wear of the cutter on the rear surface $[\mu \mathrm{m}]$ and

$T^{\circ}$ the cutting zone temperature $\left[{ }^{\circ} \mathrm{C}\right]$.

Under the condition of wear of the cutter along the back surface $h_{z}=1 \mathrm{~mm}$, the authors experimentally determined that $0.8 \mathrm{~mm}^{3}$ of carbon diffuses from the cutter during the resistance period. Recounting the data of [28], the temperature dependence of the diffusion rate was obtained and tabulated in Table 2.

Tab. 2 Diffusion wear rate of a diamond tool $[28]^{*}$.

\begin{tabular}{|c|c|c|c|c|c|}
\hline \multirow{2}{*}{ Indicators } & \multicolumn{5}{|c|}{ Temperature [ $\left.{ }^{0} \mathbf{C}\right]$} \\
\cline { 2 - 6 } & 250 & 350 & 500 & 650 & 850 \\
\hline Cutting speed $V[\mathrm{~m} / \mathrm{s}]$ & 2 & 2.5 & 3.3 & 5 & 8.4 \\
\hline Durability $T[\mathrm{~s}]$ & 625000 & 130000 & 24300 & 5000 & 2160 \\
\hline $\begin{array}{c}\text { Diffusion wear speed } \\
V_{d} \times 10^{-4}\left[\mathrm{~mm}^{3} / \mathrm{min}\right]\end{array}$ & 0.8 & 3.7 & 19.7 & 96 & 222 \\
\hline
\end{tabular}

*The surface refinement of the SD is ensured by diffusion processes occurring between the iron-containing metal binder of the grinding wheel and the microroughness remaining on the surface of the polycrystalline material after the previous stage of production processing.

The refinement process is carried out at ultrahigh speeds, more than $180 \mathrm{~m} / \mathrm{s}$, with the cutting wheel topography control system turned off and with the supply of lubricating coolant turned off, namely under the condition of mass formation of wear areas on grains. If an iron-based metal binder M6-14 is used, then the problem of the maximum possible retention of diamond grains is solved, and most importantly, the properties inherent in diamonds can be used; a high degree of chemical affinity with ferrous metals and, as a consequence, a high probability of intense diffusion mass transfer from SD in the iron binder. In the case examined in this paper, the iron binder will contribute to the diffusion removal of microroughnesses from the treated surface of SD.
The developed subsystem of the theoretical module of the expert system of diamond grinding allows the determination of the conditions of thermally activated fine-tuning of blade tools from SD. Calculations have shown that even with gentle thermal re-dosing regimes for $1-2 \mathrm{~min}$, a volume of material that is within the roughness of the previously treated surface can be removed from the surface of the SD. The volume of material constituting the irregularities of the pre-treated surface of the SD was determined by laser scanning. The most objective parameter characterizing the roughness of the machined SD surface was the value of the relative reference surface area $t_{\mathrm{ps}}$. The effect of the duration of thermally activated lapping on the value of $t_{\mathrm{ps}}$ is given in Table 3.

Tab. 3 Effect of the duration of thermally activated refinement on the value of the relative reference area $t_{p s}$ of the SD surface

\begin{tabular}{|c|c|c|c|c|c|}
\hline \multirow{2}{*}{ Roughness indicator } & \multicolumn{5}{|c|}{ Refinement time [s] } \\
\cline { 2 - 6 } & 20 & 40 & 60 & 80 & 100 \\
\hline $\begin{array}{c}t_{p s}[\%] \\
\text { with } P=10 \%\end{array}$ & 5.7 & 15.3 & 28.7 & 46.4 & 64.4 \\
\hline
\end{tabular}

The possibility of performing productive and precision machining with the same wheel, including coarse-grained has been proved and realized due to purposeful transformation of the process from mutual brittle micro-fracture of elements of the "SD - binder - grain" system to thermally activated (diffusion, graphitization, oxidation) removals during contact with a metal binder. In order to intensify the process of thermally activated refinement, an iron-based metal binder was used, which provides maximum retention strength of diamond grains and, due to the high degree of affinity of diamond with ferrous metals, a high intensity of diffusion removal of microroughnesses from the machined surface of SD. Thus, it became possible to carry out preliminary and precision operations of processing SD with the same diamond wheel on a strong metal binder based on iron. In this case, the surface roughness is significantly improved as can be seen in Fig. 5. 


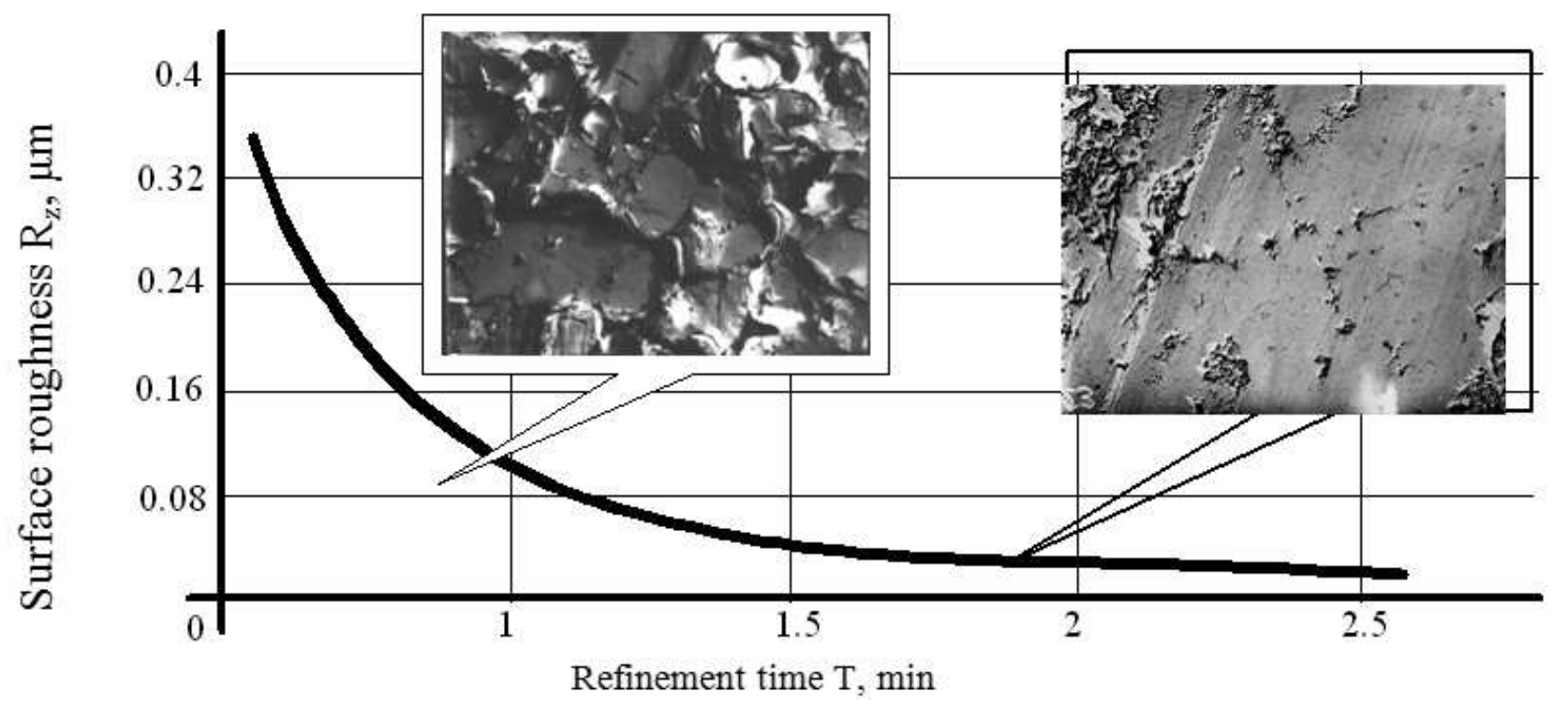

Fig. 5 Dependence of the surface roughness of SD on the time of finishing.

For the practical implementation of the research results, a simplified approach has been proposed for determining the conditions for ultra-high-speed sharpening and refinement of a blade tool from SD. At the stage of roughing, an ultra-high speed of the wheel is realized, the value of which is calculated from the empirical dependence:

Where:

$$
\mathrm{V}_{\text {rough }}=\frac{6440 K_{d y n}}{d k^{0.75}}
$$

$\mathrm{V}_{\text {rough }}$ the wheel speed during roughing in $[\mathrm{m} / \mathrm{s}]$,

$K_{\text {dyn }}$ the coefficient of dynamic strength of diamond grains and

$\mathrm{dk}$ the wheel diameter [mm].

In this case, at the second stage, the supply of the process fluid is interrupted, and the speed of the wheel is reduced to the usual level $\left(V_{2}\right)$ in accordance with the expression:

$$
\mathrm{V}_{2}=0.2 \mathrm{~V} \text { rough }
$$

At this speed, the grains stop to self-sharpening and wear out to the binder in 30-60s. The iron binder of the diamond wheel begins to come into contact with the sharpened SD. At the third stage, the speed is increased so that the temperature rises in the contact zone of the binder with the rough surface of the cutter and again at high speed due to thermal oxidative and diffusion processes (diffusion wear), the surface roughness micro-hills are removed from the diamond surface, i.e. the sharpened cutter is being refined. Thus, the performance of the process at the draft stage is ensured by activating the process of self- sharpening of diamond grains of the wheel due to the use of high speed grinding.

With increasing speed of the wheel, on the one hand, the modulus of elasticity of the binder of the wheel increases, which increases the stiffness of the technological system, and on the other hand, natural vibrations in the cutting zone are amplified. In combination, this has a positive effect on the process of selfsharpening of diamond grains of the wheel. On their surface, micro- and submicro-edges are formed, which is the key to intensifying the removal of stock from the surface of SD. The surface roughness in this case has an increased but stable value.

It was established that to determine the speed of the wheel, it is sufficient to take into account parameters such as the dynamic strength of diamond grains, as well as the size (diameter) of the grinding wheel according to eq. (5). The greater the value of the dynamic strength of the grains, the greater the speed of the wheel is needed for their self-sharpening. The larger the size of the wheel, the greater the likelihood (purely technically) of its break in conditions of ultrahigh processing speeds. Therefore, for large wheels, the optimal speed should be less important. This approach is also taken into account by eq. (5). At the finishing stage, the intensification of the material removal process occurs due to the use of such physical effects of smoothing the micro-ridges of the surface of diamond products as oxidation, diffusion, and graphitization, namely the thermo-active treatment. These effects are manifested due to the high grinding temperature, which occurs under the conditions of the processing process without supplying the process fluid to the cutting zone, even when using processing speeds in the usual range. In this case, the optimum temperature value in the processing zone takes place when the grinding wheel speed value is set according to eq. (6).

The conducted experimental studies when sharpening a blade tool from SD confirmed the hypothesis that it is possible to draft and finish machining a blade tool from SD in the same wheel at different grinding 
speeds. Fig. 6(a) shows the results of scanning 3D topography of the machined surface of a blade tool made of SD after the first high-speed, while Fig. 6(b) shows the third thermally activated sharpening stages.

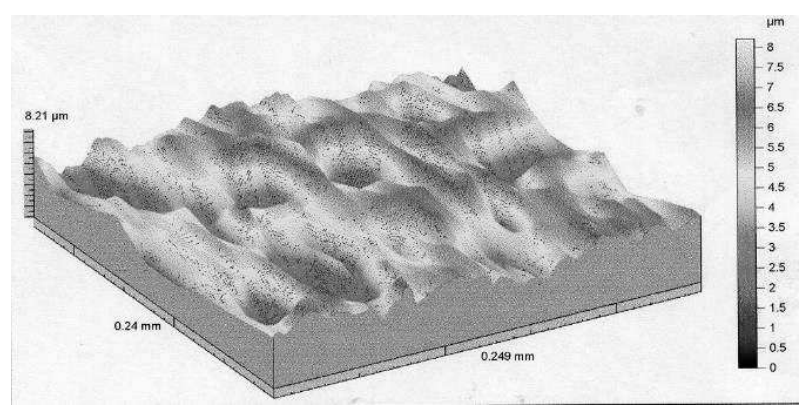

a)

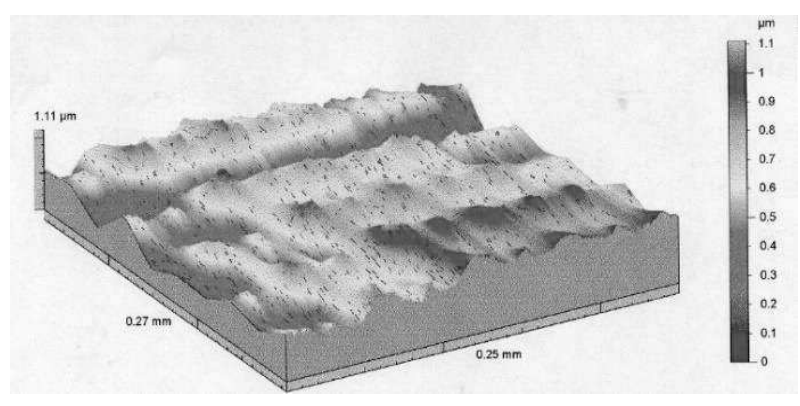

b)

Fig. 63D topography of the machined surface of the blade tool from SD (a) after the first processing step at high-speed $V 1=180 \mathrm{~m} / \mathrm{s}$ and (b) third thermally activated V2 $=30$ $\mathrm{m} / \mathrm{s}$ processing step. Processing conditions: diamond wheel 12A2-45, $150 \times 20 \times 3 \times 32$ AS6 160/125 M6-14 100\%.

\section{Conclusions}

In this paper a methodological approach is applied, which is based on the widespread use of modeling, taking into account the characteristic features of the grinding processes, with the maximum involvement of experimental data. From the performed analysis:

- It is proved that the process of forming SD can be carried out in three stages with the same diamond wheel

- A positive technical result consists in the fact that at the rough stage of sharpening a tool from SD due to ultra-high processing speeds, conditions are created to ensure continuous self-sharpening of diamond grains.

- At the final processing stage, conditions are created for using the corresponding physical effects (oxidation, diffusion, graphitization), which are manifested due to the high grinding temperature, which occurs at ultra-high speed refinement and in the conditions of the processing process without feeding the cutting zone with the cooling fluid.

- With increasing speed of the wheel, on the one hand, the modulus of elasticity of the binder of the wheel increases, which increases the rigidity of the technological system, and on the other hand, natural vibrations in the cutting zone are amplified. In combination, these effects positively affect the process of self-sharpening of diamond grains of the wheel.

Based on the results of studies, it was concluded that it is advisable to use a diamond around the iron binder M6-14 for all stages of grinding.

\section{References}

[1] KUNDRÁK, J., FEDOROVICH, V., PYZHOV, I., MARKOPOULOS, A.P. (2019). Improving the effectiveness of combined grinding processes for processing superhard materials. Journal of Manufacturing Processes. Vol. 43, Part A, pp. 270-275. 10.1016/j.jmapro.2019.05.004

[2] KUNDRÁK, J., FEDORENKO, D.O., FEDOROVICH, V.A., FEDORENKO, E.Y., OSTROVERKH, E.V. (2019). Porous diamond grinding wheels on ceramic binders: Design and manufacturing. Manufacturing Technology. 19(3), pp. 446-454. 10.21062/ujep/311.2019/a/12132489/MT/19/3/446

[3] TANIGUCHI, N. (1982). Polishing and sharpening of diamond point tools by ion sputtermachining. Precision Engineering. 4(4), pp. 191194. 10.1016/0141-6359(82)90004-6

[4] SATO, Y., KAWAMURA, J., NAGASE, T., PAHLOVY, S.A., MIYAMOTO, I. (2011). Sharpening of CVD diamond coated tools by $0.5-10 \mathrm{keV}$ Ar+ ion beam. Diamond and Related Materials. 20(7), pp. 954-959. 10.1016/j.diamond.2011.04.008

[5] ZONG, W.J., SUN, T., LI, D., CHENG, K., LI, Z.Q. (2008). Nano-precision diamond cutting tools achieved by mechanical lapping versus thermo-mechanical lapping. Diamond and Related Materials. 17(6), pp. 54-961. 10.1016/j.diamond.2008.02.018

[6] YANG, K., XIA, Y., LI, L., HE, N., ZHANG, Y., ZHANG, T., WANG, Y. (2018). Experimental study on hybrid machining of laser irradiation and grinding for sharpening of a CVD diamond micro-milling tool. International Journal 
of Advanced Manufacturing Technology. 96, pp. 327336. $10.1007 / \mathrm{s} 00170-018-1624-7$

[7] MAMALIS, A.G., GRABCHENKO, A.I., FEDOROVICH, V.A., GRINKO, S.A., PAULMIER, D., HORVATH, M. (2001). Development of an expert system of diamond grinding of superhard polycrystalline materials considering grinding wheel relief. International Journal of Advanced Manufacturing Technology. 17(7), pp. 498-507. 10.1007/s001700170150

[8] LIAO, T.W., LI, K., MCSPADDEN, S.B. (2000). Wear mechanisms of diamond abrasives during transition and steady stages in creep-feed grinding of structural ceramics. Wear. 242, pp. 28-37. 10.1016/S00431648(00)00366-5

[9] KONIECZNY, A., RUSINSKI, E., MOCZKO, P., PAWLOS, W., STAMBOLISKA, Z. (2014). The influence of copper ore lithology on the grinding media wear. Wear. 318, pp. 40-48. 10.1016/j.wear.2014.06.009

[10] ZHU, Y., DING, W., RAO, Z., FU, Y. (2019). Effect of grinding wheel speed on self-sharpening ability of PCBN grain during grinding of nickel-based superalloys with a constant undeformed chip thickness. Wear. 426-427, pp. 1573-1583. 10.1016/j.wear.2018.12.064

[11] CHEN, T.J., LEE, R.T., CHIOU, Y.C. (2013). Finish machining of mirror-like diamond surfaces using a composite electroplating in-process sharpening method. Proceedings of the Institution of Mechanical Engineers, Part B: Journal of Engineering Manufacture. 227, pp. 1596-1606. 10.1177/0954405413480496

[12] MAREK, M., NOVÁK, M. ŠRAMHAUSER, K. (2019). The impact of changes in infeed rate on surface integrity after chrome plate grinding by silicon carbide. Manufacturing Technology. 19(2), $\quad$ pp. 284-291. 10.21062/ujep/284.2019/a/12132489/MT/19/2/284

[13] MAREK, M., NOVÁK, M. ŠRAMHAUSER, K. (2019). The impact of changes in infeed rate on surface integrity after chrome plate grinding by microcrystalline corundum. Manufacturing Technology. 19(3), pp. 461-468. 10.21062/ujep/313.2019/a/12132489/MT/19/3/461

[14] SHEN, J.Y., WANG, J.Q., JIANG, B., XU, X.P. (2015). Study on wear of diamond wheel in ultrasonic vibration-assisted grinding ceramic. Wear. 332-333, pp. 788-793. 10.1016/j.wear.2015.02.047

[15] YANG, K., XIA, Y., LI, L., HE, N., ZHANG, Y., ZHANG, T., WANG, Y. (2018). Experimental study on hybrid machining of laser irradiation and grinding for sharpening of a CVD diamond micro-milling tool. International Journal of Advanced Manufacturing Technology. 96, pp 327336. 10.1007/s00170-018-1624-7

[16] ZONG, W.J., LI, D., SUN, T., CHENG, K. (2006). Contact accuracy and orientations affecting the lapped tool sharpness of diamond cutting tools by mechanical lapping. Diamond and Related Materials. 15, pp. 1424-1433. 10.1016/j.diamond.2005.10.066

[17] KUNDRÁK, J., FEDOROVICH, V., MARKOPOULOS, A.P., PYZHOV, I., KRYUKOVA, N. (2016). Diamond grinding wheels production study with the use of the finite element method. Journal of Advanced Research. 7(6), pp. 1057-1064. 10.1016/j.jare.2016.08.003

[18] KUNDRÁK, J., FEDOROVICH, V., PYZHOV, I., MARKOPOULOS, A.P., KLIMENKO, V., KRYUKOVA, N. (2017). Theoretical analysis of the contact area between grinding wheel surface and workpiece in flat face grinding with spindle axis inclination. $\mathrm{Ma}$ nufacturing Technology. 17(2), pp. 203-210. $10.21062 /$ ujep/x.2017/a/12132489/MT/17/2/203

[19] WEBSTER, J., TRICARD, M. (2004). Innovations in Abrasive Products for Precision Grinding. Annals of the CIRP. 53(2), pp. 597-617. 10.1016/S0007-8506(07)60031-6

[20] Brinksmeier, E., Aurich, J.C., Govekar, E., Heinzel, C., Hoffmeister, H.-W., Klocke, F., Peters, J., Rentsch, R., Stephenson, D.J., Uhlmann, E., Weinert, K., Wittmann, M. (2006). Advances in Modeling and Simulation of Grinding Processes. Annals of the CIRP. 57(2), pp. 667-696. 10.1016/j.cirp.2006.10.003

[21] LI, W., WANG, Y., FAN, S.H., XU, J.F. (2007). Wear of diamond grinding wheels and material removal rate of silicon nitrides under different machining conditions. Materials Letters. 61(1), pp. 54-58. 10.1016/j.matlet.2006.04.004

[22] OLIVEIRA, J.F.G., SILVA, E.J., GUO, C., HASHIMOTO, F. (2009) Industrial challenges in grinding. Annals of the CIRP. 58(2), pp. 663680. 10.1016/j.cirp.2009.09.006 
[23] KRAMER, D., REHSTEINER, F., SCHUMACHER, B. (1999). ECD (Electrochemical In-Process Controlled Dressing), a New Method for Grinding of Modern High-Performance Cutting Materials to Highest Quality. Annals of the CIRP. 48(1), pp. 265-268. 10.1016/S0007-8506(07)63180-1

[24] JACKSON, M.J., DAVIS, C.J., HITCHINER, M.P., MILLS, B. (2001). High-Speed Grinding with c.B.N. Grinding Wheels - Applications and Future Developments. Journal of Materials Processing Technology. 110, pp. 78-88. 10.1016/S0924-0136(00)00869-4

[25] BAKSA, T., FARSKY, J., HRONEK, O., ZETEK, M. (2019). Surface quality after grinding VACO 180 tool steel using different cutting conditions. Manufacturing Technology, $19(2)$ pp. 179-183. 10.21062/ujep/266.2019/a/12132489/MT/19/2/179
[26] VASVÁRY, L., DITRÓI, F., TAKÁCS, S., SZABÓ, Z., SZUCS, J., KUNDRÁK, J., MAHUNKA, I. (1994). Wear measurement of the cutting edge of super-hard turning tools using TLA technique. Nuclear Instruments and Methods in Physics Research Section B: Beam Interaction with Materials and Atoms. 85(1-4), pp. 255259. 10.1016/0168-583X(94)95822-X

[27] LOLADZE, T.N., BOKUCHAVA, G.B. (1967). Wear of diamonds and diamond wheels. Mechanical Engineering, Moscow 1967, p. 112.

[28] LOLADZE, T.N., BOKUCHAVA, G.V. (1985). Theory of Diffusion Wear of Diamond Abrasive Tools. Tr. VNILASH. No. 5: 103112.

[29] KHODOREVSKY, M.G. (1975). Investigation of the process of diamond grinding of synthetic superhard materials. Dis. cand. tech. Sciences. P. 214.

[30] CHEREPANOV, G.P. (1974). Mechanics of brittle fracture. Science, Moscow. p. 640. 